\title{
Coupled fixed point theorems for $\alpha-\psi$-contractive type mappings in partially ordered metric spaces
}

\author{
Mohammad Mursaleen ${ }^{1}$, Syed Abdul Mohiuddine ${ }^{2^{*}}$ and Ravi P Agarwal ${ }^{3,2}$
}

"Correspondence:

mohiuddine@gmail.com

${ }^{2}$ Department of Mathematics,

Faculty of Science, King Abdulaziz

University, P.O. Box 80203, Jeddah,

21589, Saudi Arabia

Full list of author information is

available at the end of the article

\begin{abstract}
The object of this paper is to determine some coupled fixed point theorems for nonlinear contractive mappings in the framework of a metric space endowed with partial order. We also prove the uniqueness of a coupled fixed point for such mappings in this setup.

MSC: $47 \mathrm{H} 10 ; 54 \mathrm{H} 25 ; 34 \mathrm{~B} 15$

Keywords: coupled fixed point; contractive mapping; partially ordered set; metric space
\end{abstract}

\section{Introduction}

Fixed point theory is a very useful tool in solving a variety of problems in control theory, economic theory, nonlinear analysis and global analysis. The Banach contraction principle [1] is the most famous, simplest and one of the most versatile elementary results in fixed point theory. A huge amount of literature is witnessed on applications, generalizations and extensions of this principle carried out by several authors in different directions, e.g., by weakening the hypothesis, using different setups, considering different mappings.

Many authors obtained important fixed point theorems, e.g., Abbas et al. [2], Agarwal et al. [3, 4], Bhaskar and Lakshmikantham [5], Choudhury and Kundu [6], Choudhury and Maity [7], Ćirić et al. [8], Luong and Thuan [9], Nieto and López [10, 11], Ran and Reurings [12] and Samet [13] presented some new results for contractions in partially ordered metric spaces. In [14], Ilić and Rakočević determined some common fixed point theorems by considering the maps on cone metric spaces. Recently, Haghi et al. [15] have shown that some coincidence point and common fixed point generalizations in fixed point theory are not real generalizations. For more detail on fixed point theory and related concepts, we refer to [16-34] and the references therein.

In [5], Bhaskar and Lakshmikantham introduced the notions of mixed monotone property and coupled fixed point for the contractive mapping $F: X \times X \rightarrow X$, where $X$ is a partially ordered metric space, and proved some coupled fixed point theorems for a mixed monotone operator. As an application of the coupled fixed point theorems, they determined the existence and uniqueness of the solution of a periodic boundary value problem. Recently, Lakshmikantham and Ćirić [35] have proved coupled coincidence and coupled common fixed point theorems for nonlinear contractive mappings in partially ordered complete metric spaces. Most recently, Samet et al. [36] have defined $\alpha$ - $\psi$-contractive

(c) 2012 Mursaleen et al.; licensee Springer. This is an Open Access article distributed under the terms of the Creative Commons Attribution License (http://creativecommons.org/licenses/by/2.0), which permits unrestricted use, distribution, and reproduction in any medium, provided the original work is properly cited. 
and $\alpha$-admissible mapping and proved fixed point theorems for such mappings in complete metric spaces.

The aim of this paper is to determine some coupled fixed point theorems for generalized contractive mappings in the framework of partially ordered metric spaces.

\section{Definitions and preliminary results}

We start with the definition of a mixed monotone property and a coupled fixed point and state the related results.

Definition 2.1 ([5]) Let $(X, \leq)$ be a partially ordered set and $F: X \times X \rightarrow X$ be a mapping. Then a map $F$ is said to have the mixed monotone property if $F(x, y)$ is monotone nondecreasing in $x$ and is monotone non-increasing in $y$; that is, for any $x, y \in X$,

$$
x_{1}, x_{2} \in X, \quad x_{1} \leq x_{2} \quad \text { implies } \quad F\left(x_{1}, y\right) \leq F\left(x_{2}, y\right)
$$

and

$$
y_{1}, y_{2} \in X, \quad y_{1} \leq y_{2} \quad \text { implies } \quad F\left(x, y_{1}\right) \geq F\left(x, y_{2}\right) .
$$

Definition 2.2 ([5]) An element $(x, y) \in X \times X$ is said to be a coupled fixed point of the mapping $F: X \times X \rightarrow X$ if

$$
F(x, y)=x \quad \text { and } \quad F(y, x)=y .
$$

Theorem 2.3 ([5]) Let $(X, \leq)$ be a partially ordered set and suppose there is a metric $d$ on $X$ such that $(X, d)$ is a complete metric space. Let $F: X \times X \rightarrow X$ be a continuous mapping having the mixed monotone property on $X$. Assume that there exists a $k \in[0,1)$ with

$$
d(F(x, y), F(u, v)) \leq \frac{k}{2}[d(x, u)+d(y, v)]
$$

for all $x \geq u$ and $y \leq v$. If there exist $x_{0}, y_{0} \in X$ such that

$$
x_{0} \leq F\left(x_{0}, y_{0}\right) \text { and } y_{0} \geq F\left(y_{0}, x_{0}\right) \text {, }
$$

then there exist $x, y \in X$ such that $F(x, y)=x$ and $F(y, x)=y$.

Theorem 2.4 ([5]) Let $(X, \leq)$ be a partially ordered set and suppose there is a metric $d$ on $X$ such that $(X, d)$ is a complete metric space. Assume that $X$ has the following property:

(i) if a non-decreasing sequence $\left(x_{n}\right) \rightarrow x$, then $x_{n} \leq x$ for all $n$;

(ii) if a non-increasing sequence $\left(y_{n}\right) \rightarrow y$, then $y \leq y_{n}$ for all $n$.

Let $F: X \times X \rightarrow X$ be a mapping having the mixed monotone property on $X$. Assume that there exists a $k \in[0,1)$ with

$$
d(F(x, y), F(u, v)) \leq \frac{k}{2}[d(x, u)+d(y, v)]
$$

for all $x \geq u$ and $y \leq v$. If there exist $x_{0}, y_{0} \in X$ such that

$$
x_{0} \leq F\left(x_{0}, y_{0}\right) \quad \text { and } \quad y_{0} \geq F\left(y_{0}, x_{0}\right)
$$

then there exist $x, y \in X$ such that $F(x, y)=x$ and $F(y, x)=y$. 


\section{Main results}

In this section, we establish some coupled fixed point results by considering maps on metric spaces endowed with partial order.

Denote by $\Psi$ the family of non-decreasing functions $\psi:[0,+\infty) \rightarrow[0,+\infty)$ such that $\sum_{n=1}^{\infty} \psi^{n}(t)<\infty$ for all $t>0$, where $\psi^{n}$ is the $n$th iterate of $\psi$ satisfying (i) $\psi^{-1}(\{0\})=\{0\}$, (ii) $\psi(t)<t$ for all $t>0$ and (iii) $\lim _{r \rightarrow t^{+}} \psi(r)<t$ for all $t>0$.

Lemma 3.1 If $\psi:[0, \infty] \rightarrow[0, \infty]$ is non-decreasing and right continuous, then $\psi^{n}(t) \rightarrow 0$ as $n \rightarrow \infty$ for all $t \geq 0$ if and only if $\psi(t)<t$ for all $t>0$.

Definition 3.2 Let $(X, d)$ be a partially ordered metric space and $F: X \times X \rightarrow X$ be a mapping. Then a map $F$ is said to be $(\alpha, \psi)$-contractive if there exist two functions $\alpha$ : $X^{2} \times X^{2} \rightarrow[0,+\infty)$ and $\psi \in \Psi$ such that

$$
\alpha((x, y),(u, v)) d(F(x, y), F(u, v)) \leq \psi\left(\frac{d(x, u)+d(y, v)}{2}\right)
$$

for all $x, y, u, v \in X$ with $x \geq u$ and $y \leq v$.

Definition 3.3 Let $F: X \times X \rightarrow X$ and $\alpha: X^{2} \times X^{2} \rightarrow[0,+\infty)$ be two mappings. Then $F$ is said to be $(\alpha)$-admissible if

$$
\alpha((x, y),(u, v)) \geq 1 \quad \Longrightarrow \quad \alpha((F(x, y), F(y, x)),(F(u, v), F(v, u))) \geq 1
$$

for all $x, y, u, v \in X$.

Theorem 3.4 Let $(X, \leq)$ be a partially ordered set and suppose there is a metric $d$ on $X$ such that $(X, d)$ is a complete metric space. Let $F: X \times X \rightarrow X$ be a mapping having the mixed monotone property of $X$. Suppose that there exist $\psi \in \Psi$ and $\alpha: X^{2} \times X^{2} \rightarrow[0,+\infty)$ such that for $x, y, u, v \in X$, the following holds:

$$
\alpha((x, y),(u, v)) d(F(x, y), F(u, v)) \leq \psi\left(\frac{d(x, u)+d(y, v)}{2}\right)
$$

for all $x \geq u$ and $y \leq v$. Suppose also that

(i) $F$ is $(\alpha)$-admissible,

(ii) there exist $x_{0}, y_{0} \in X$ such that

$$
\alpha\left(\left(x_{0}, y_{0}\right),\left(F\left(x_{0}, y_{0}\right), F\left(y_{0}, x_{0}\right)\right)\right) \geq 1 \quad \text { and } \quad \alpha\left(\left(y_{0}, x_{0}\right),\left(F\left(y_{0}, x_{0}\right), F\left(x_{0}, y_{0}\right)\right)\right) \geq 1 \text {, }
$$

(iii) $F$ is continuous.

If there exist $x_{0}, y_{0} \in X$ such that $x_{0} \leq F\left(x_{0}, y_{0}\right)$ and $y_{0} \geq F\left(y_{0}, x_{0}\right)$, then $F$ has a coupled fixed point; that is, there exist $x, y \in X$ such that

$$
F(x, y)=x \quad \text { and } \quad F(y, x)=y .
$$

Proof Let $x_{0}, y_{0} \in X$ be such that $\alpha\left(\left(x_{0}, y_{0}\right),\left(F\left(x_{0}, y_{0}\right), F\left(y_{0}, x_{0}\right)\right)\right) \geq 1$ and $\alpha\left(\left(y_{0}, x_{0}\right)\right.$, $\left.\left(F\left(y_{0}, x_{0}\right), F\left(x_{0}, y_{0}\right)\right)\right) \geq 1$ and $x_{0} \leq F\left(x_{0}, y_{0}\right)=x_{1}$ (say) and $y_{0} \geq F\left(y_{0}, x_{0}\right)=y_{1}$ (say). Let 
$x_{2}, y_{2} \in X$ be such that $F\left(x_{1}, y_{1}\right)=x_{2}$ and $F\left(y_{1}, x_{1}\right)=y_{2}$. Continuing this process, we can construct two sequences $\left(x_{n}\right)$ and $\left(y_{n}\right)$ in $X$ as follows:

$$
x_{n+1}=F\left(x_{n}, y_{n}\right) \text { and } y_{n+1}=F\left(y_{n}, x_{n}\right)
$$

for all $n \geq 0$. We will show that

$$
x_{n} \leq x_{n+1} \quad \text { and } \quad y_{n} \geq y_{n+1}
$$

for all $n \geq 0$. We will use the mathematical induction. Let $n=0$. Since $x_{0} \leq F\left(x_{0}, y_{0}\right)$ and $y_{0} \geq F\left(y_{0}, x_{0}\right)$ and as $x_{1}=F\left(x_{0}, y_{0}\right)$ and $y_{1}=F\left(y_{0}, x_{0}\right)$, we have $x_{0} \leq x_{1}$ and $y_{0} \geq y_{1}$. Thus, (3.2) hold for $n=0$. Now suppose that (3.2) hold for some fixed $n, n \geq 0$. Then, since $x_{n} \leq x_{n+1}$ and $y_{n} \geq y_{n+1}$ and by the mixed monotone property of $F$, we have

$$
x_{n+2}=F\left(x_{n+1}, y_{n+1}\right) \geq F\left(x_{n}, y_{n+1}\right) \geq F\left(x_{n}, y_{n}\right)=x_{n+1}
$$

and

$$
y_{n+2}=F\left(y_{n+1}, x_{n+1}\right) \leq F\left(y_{n}, x_{n+1}\right) \leq F\left(y_{n}, x_{n}\right)=y_{n+1} \text {. }
$$

From above, we conclude that

$$
x_{n+1} \leq x_{n+2} \quad \text { and } \quad y_{n+1} \geq y_{n+2} \text {. }
$$

Thus, by the mathematical induction, we conclude that (3.2) hold for all $n \geq 0$. If for some $n$ we have $\left(x_{n+1}, y_{n+1}\right)=\left(x_{n}, y_{n}\right)$, then $F\left(x_{n}, y_{n}\right)=x_{n}$ and $F\left(y_{n}, x_{n}\right)=y_{n}$; that is, $F$ has a coupled fixed point. Now, we assumed that $\left(x_{n+1}, y_{n+1}\right) \neq\left(x_{n}, y_{n}\right)$ for all $n \geq 0$. Since $F$ is $(\alpha)$ admissible, we have

$$
\begin{aligned}
& \alpha\left(\left(x_{0}, y_{0}\right),\left(x_{1}, y_{1}\right)\right)=\alpha\left(\left(x_{0}, y_{0}\right),\left(F\left(x_{0}, y_{0}\right), F\left(y_{0}, x_{0}\right)\right)\right) \geq 1 \\
& \quad \Longrightarrow \quad \alpha\left(\left(F\left(x_{0}, y_{0}\right), F\left(y_{0}, x_{0}\right)\right),\left(F\left(x_{1}, y_{1}\right), F\left(y_{1}, x_{1}\right)\right)\right)=\alpha\left(\left(x_{1}, y_{1}\right),\left(x_{2}, y_{2}\right)\right) \geq 1 .
\end{aligned}
$$

Thus, by the mathematical induction, we have

$$
\alpha\left(\left(x_{n}, y_{n}\right),\left(x_{n+1}, y_{n+1}\right)\right) \geq 1
$$

and similarly,

$$
\alpha\left(\left(y_{n}, x_{n}\right),\left(y_{n+1}, x_{n+1}\right)\right) \geq 1
$$

for all $n \in \mathbb{N}$. Using (3.1) and (3.3), we obtain

$$
\begin{aligned}
d\left(x_{n}, x_{n+1}\right) & =d\left(F\left(x_{n-1}, y_{n-1}\right), F\left(x_{n}, y_{n}\right)\right) \\
& \leq \alpha\left(\left(x_{n-1}, y_{n-1}\right),\left(x_{n}, y_{n}\right)\right) d\left(F\left(x_{n-1}, y_{n-1}\right), F\left(x_{n}, y_{n}\right)\right) \\
& \leq \psi\left(\frac{d\left(x_{n-1}, x_{n}\right)+d\left(y_{n-1}, y_{n}\right)}{2}\right) .
\end{aligned}
$$


Similarly, we have

$$
\begin{aligned}
d\left(y_{n}, y_{n+1}\right) & =d\left(F\left(y_{n-1}, y_{n-1}\right), F\left(y_{n}, y_{n}\right)\right) \\
& \leq \alpha\left(\left(y_{n-1}, x_{n-1}\right),\left(y_{n}, x_{n}\right)\right) d\left(F\left(y_{n-1}, x_{n-1}\right), F\left(y_{n}, x_{n}\right)\right) \\
& \leq \psi\left(\frac{d\left(y_{n-1}, y_{n}\right)+d\left(x_{n-1}, x_{n}\right)}{2}\right) .
\end{aligned}
$$

Adding (3.5) and (3.6), we get

$$
\frac{d\left(x_{n}, x_{n+1}\right)+d\left(y_{n}, y_{n+1}\right)}{2} \leq \psi\left(\frac{d\left(x_{n-1}, x_{n}\right)+d\left(y_{n-1}, y_{n}\right)}{2}\right) .
$$

Repeating the above process, we get

$$
\frac{d\left(x_{n}, x_{n+1}\right)+d\left(y_{n}, y_{n+1}\right)}{2} \leq \psi^{n}\left(\frac{d\left(x_{0}, x_{1}\right)+d\left(y_{0}, y_{1}\right)}{2}\right)
$$

for all $n \in \mathbb{N}$. For $\epsilon>0$ there exists $n(\epsilon) \in \mathbb{N}$ such that

$$
\sum_{n \geq n(\epsilon)} \psi^{n}\left(\frac{d\left(x_{0}, x_{1}\right)+d\left(y_{0}, y_{1}\right)}{2}\right)<\epsilon / 2
$$

Let $n, m \in \mathbb{N}$ be such that $m>n>n(\epsilon)$. Then, by using the triangle inequality, we have

$$
\begin{aligned}
\frac{d\left(x_{n}, x_{m}\right)+d\left(y_{n}, y_{m}\right)}{2} & \leq \sum_{k=n}^{m-1} \frac{d\left(x_{k}, x_{k+1}\right)+d\left(y_{k}, y_{k+1}\right)}{2} \\
& \leq \sum_{k=n}^{m-1} \psi^{k}\left(\frac{d\left(x_{0}, x_{1}\right)+d\left(y_{0}, y_{1}\right)}{2}\right) \\
& \leq \sum_{n \geq n(\epsilon)} \psi^{n}\left(\frac{d\left(x_{0}, x_{1}\right)+d\left(y_{0}, y_{1}\right)}{2}\right)<\epsilon / 2 .
\end{aligned}
$$

This implies that $d\left(x_{n}, x_{m}\right)+d\left(y_{n}, y_{m}\right)<\epsilon$. Since

$$
d\left(x_{n}, x_{m}\right) \leq d\left(x_{n}, x_{m}\right)+d\left(y_{n}, y_{m}\right)<\epsilon
$$

and

$$
d\left(y_{n}, y_{m}\right) \leq d\left(x_{n}, x_{m}\right)+d\left(y_{n}, y_{m}\right)<\epsilon,
$$

and hence $\left(x_{n}\right)$ and $\left(y_{n}\right)$ are Cauchy sequences in $(X, d)$. Since $(X, d)$ is a complete metric space and hence $\left(x_{n}\right)$ and $\left(y_{n}\right)$ are convergent in $(X, d)$. Then there exist $x, y \in X$ such that

$$
\lim _{n \rightarrow \infty} x_{n}=x \text { and } \lim _{n \rightarrow \infty} y_{n}=y .
$$

Since $F$ is continuous and $x_{n+1}=F\left(x_{n}, y_{n}\right)$ and $y_{n+1}=F\left(y_{n}, x_{n}\right)$, taking limit $n \rightarrow \infty$, we get

$$
x=\lim _{n \rightarrow \infty} x_{n}=\lim _{n \rightarrow \infty} F\left(x_{n-1}, y_{n-1}\right)=F(x, y)
$$


and

$$
y=\lim _{n \rightarrow \infty} y_{n}=\lim _{n \rightarrow \infty} F\left(y_{n-1}, x_{n-1}\right)=F(y, x)
$$

that is, $F(x, y)=x$ and $F(y, x)=y$ and hence $F$ has a coupled fixed point.

In the next theorem, we omit the continuity hypothesis of $F$.

Theorem 3.5 Let $(X, \leq)$ be a partially ordered set and suppose there is a metric $d$ on $X$ such that $(X, d)$ is a complete metric space. Let $F: X \times X \rightarrow X$ be a mapping such that $F$ has the mixed monotone property. Assume that there exist $\psi \in \Psi$ and a mapping $\alpha$ : $X^{2} \times X^{2} \rightarrow[0,+\infty)$ such that

$$
\alpha((x, y),(u, v)) d(F(x, y), F(u, v)) \leq \psi\left(\frac{d(x, u)+d(y, v)}{2}\right)
$$

for all $x, y, u, v \in X$ with $x \geq u$ and $y \leq v$. Suppose that

(i) conditions (i) and (ii) of Theorem 3.4 hold,

(ii) if $\left(x_{n}\right)$ and $\left(y_{n}\right)$ are sequences in $X$ such that

$$
\alpha\left(\left(x_{n}, y_{n}\right),\left(x_{n+1}, y_{n+1}\right)\right) \geq 1 \quad \text { and } \quad \alpha\left(\left(y_{n}, x_{n}\right),\left(y_{n+1}, x_{n+1}\right)\right) \geq 1
$$

for all $n$ and $\lim _{n \rightarrow \infty} x_{n}=x \in X$ and $\lim _{n \rightarrow \infty} y_{n}=y \in X$, then

$$
\alpha\left(\left(x_{n}, y_{n}\right),(x, y)\right) \geq 1 \quad \text { and } \quad \alpha\left(\left(x_{n}, y_{n}\right),(x, y)\right) \geq 1
$$

If there exist $x_{0}, y_{0} \in X$ such that $x_{0} \leq F\left(x_{0}, y_{0}\right)$ and $y_{0} \geq F\left(y_{0}, x_{0}\right)$, then there exist $x, y \in X$ such that $F(x, y)=x$ and $F(y, x)=y$; that is, $F$ has a coupled fixed point in $X$.

Proof Proceeding along the same lines as in the proof of Theorem 3.4, we know that $\left(x_{n}\right)$ and $\left(y_{n}\right)$ are Cauchy sequences in the complete metric space $(X, d)$. Then there exist $x, y \in$ $X$ such that

$$
\lim _{n \rightarrow \infty} x_{n}=x \text { and } \lim _{n \rightarrow \infty} y_{n}=y
$$

On the other hand, from (3.3) and hypothesis (ii), we obtain

$$
\alpha\left(\left(x_{n}, y_{n}\right),(x, y)\right) \geq 1
$$

and similarly,

$$
\alpha\left(\left(y_{n}, x_{n}\right),(y, x)\right) \geq 1
$$

for all $n \in \mathbb{N}$. Using the triangle inequality, (3.8) and the property of $\psi(t)<t$ for all $t>0$, we get

$$
\begin{aligned}
d(F(x, y), x) & \leq d\left(F(x, y), F\left(x_{n}, y_{n}\right)\right)+d\left(x_{n+1}, x\right) \\
& \leq \alpha\left(\left(x_{n}, y_{n}\right),(x, y)\right) d\left(F\left(x_{n}, y_{n}\right), F(x, y)\right)+d\left(x_{n+1}, x\right)
\end{aligned}
$$




$$
\begin{aligned}
& \leq \psi\left(\frac{d\left(x_{n}, x\right)+d\left(y_{n}, y\right)}{2}\right)+d\left(x_{n+1}, x\right) \\
& <\frac{d\left(x_{n}, x\right)+d\left(y_{n}, y\right)}{2}+d\left(x_{n+1}, x\right) .
\end{aligned}
$$

Similarly, using (3.9), we obtain

$$
\begin{aligned}
d(F(y, x), y) & \leq \alpha\left(\left(y_{n}, x_{n}\right),(y, x)\right) d\left(F\left(y_{n}, x_{n}\right), F(y, x)\right)+d\left(y_{n+1}, y\right) \\
& \leq \psi\left(\frac{d\left(y_{n}, y\right)+d\left(x_{n}, x\right)}{2}\right)+d\left(y_{n+1}, y\right) \\
& <\frac{d\left(y_{n}, y\right)+d\left(x_{n}, x\right)}{2}+d\left(y_{n+1}, y\right) .
\end{aligned}
$$

Taking the limit as $n \rightarrow \infty$ in the above two inequalities, we get

$$
d(F(x, y), x)=0 \quad \text { and } \quad d(F(y, x), y)=0 .
$$

Hence, $F(x, y)=x$ and $F(y, x)=y$. Thus, $F$ has a coupled fixed point.

In the following theorem, we will prove the uniqueness of the coupled fixed point. If $(X, \leq)$ is a partially ordered set, then we endow the product $X \times X$ with the following partial order relation:

$$
(x, y) \leq(u, v) \Longleftrightarrow x \leq u, \quad y \geq v
$$

for all $(x, y),(u, v) \in X \times X$.

Theorem 3.6 In addition to the hypothesis of Theorem 3.4, suppose that for every $(x, y)$, $(s, t)$ in $X \times X$, there exists $(u, v)$ in $X \times X$ such that

$$
\alpha((x, y),(u, v)) \geq 1 \quad \text { and } \quad \alpha((s, t),(u, v)) \geq 1 \text {, }
$$

and also assume that $(u, v)$ is comparable to $(x, y)$ and $(s, t)$. Then $F$ has a unique coupled fixed point.

Proof From Theorem 3.4, the set of coupled fixed points is nonempty. Suppose $(x, y)$ and $(s, t)$ are coupled fixed points of the mappings $F: X \times X \rightarrow X$; that is, $x=F(x, y), y=F(y, x)$ and $s=F(s, t), t=F(t, s)$. By assumption, there exists $(u, v)$ in $X \times X$ such that $(u, v)$ is comparable to $(x, y)$ and $(s, t)$. Put $u=u_{0}$ and $v=v_{0}$ and choose $u_{1}, v_{1} \in X$ such that $u_{1}=$ $F\left(u_{1}, v_{1}\right)$ and $v_{1}=F\left(v_{1}, u_{1}\right)$. Thus, we can define two sequences $\left(u_{n}\right)$ and $v_{n}$ as

$$
u_{n+1}=F\left(u_{n}, v_{n}\right) \quad \text { and } \quad v_{n+1}=F\left(v_{n}, u_{n}\right)
$$

Since $(u, v)$ is comparable to $(x, y)$, it is easy to show that $x \leq u_{1}$ and $y \geq v_{1}$. Thus, $x \leq u_{n}$ and $y \geq v_{n}$ for all $n \geq 1$. Since for every $(x, y),(s, t) \in X \times X$, there exists $(u, v) \in X \times X$ such that

$$
\alpha((x, y),(u, v)) \geq 1 \quad \text { and } \quad \alpha((s, t),(u, v)) \geq 1
$$


Since $F$ is $(\alpha)$-admissible, so from (3.10), we have

$$
\alpha((x, y),(u, v)) \geq 1 \quad \Longrightarrow \quad \alpha((F(x, y), F(y, x)),(F(u, v), F(v, u))) \geq 1
$$

Since $u=u_{0}$ and $v=v_{0}$, we get

$$
\alpha((x, y),(u, v)) \geq 1 \quad \Longrightarrow \quad \alpha\left((F(x, y), F(y, x)),\left(F\left(u_{0}, v_{0}\right), F\left(v_{0}, u_{0}\right)\right)\right) \geq 1 .
$$

Thus,

$$
\alpha((x, y),(u, v)) \geq 1 \quad \Longrightarrow \quad \alpha\left((x, y),\left(u_{1}, v_{1}\right)\right) \geq 1 \text {. }
$$

Therefore, by the mathematical induction, we obtain

$$
\alpha\left((x, y),\left(u_{n}, v_{n}\right)\right) \geq 1
$$

for all $n \in$ and similarly, $\alpha\left((y, x),\left(v_{n}, u_{n}\right)\right) \geq 1$. From (3.10) and (3.11), we get

$$
\begin{aligned}
d\left(x, u_{n+1}\right) & =d\left(F(x, y), F\left(u_{n}, v_{n}\right)\right) \\
& \leq \alpha\left((x, y),\left(u_{n}, v_{n}\right)\right) d\left(F(x, y), F\left(u_{n}, v_{n}\right)\right) \\
& \leq \psi\left(\frac{d\left(x, u_{n}\right)+d\left(y, v_{n}\right)}{2}\right) .
\end{aligned}
$$

Similarly, we have

$$
\begin{aligned}
d\left(y, v_{n+1}\right) & =d\left(F(y, x), F\left(v_{n}, u_{n}\right)\right) \\
& \leq \alpha\left((y, x),\left(v_{n}, u_{n}\right)\right) d\left(F(y, x), F\left(v_{n}, u_{n}\right)\right) \\
& \leq \psi\left(\frac{d\left(y, v_{n}\right)+d\left(x, u_{n}\right)}{2}\right) .
\end{aligned}
$$

Adding (3.12) and (3.13), we get

$$
\frac{d\left(x, u_{n+1}\right)+d\left(y, v_{n+1}\right)}{2} \leq \psi\left(\frac{d\left(x, u_{n}\right)+d\left(y, v_{n}\right)}{2}\right) .
$$

Thus,

$$
\frac{d\left(x, u_{n+1}\right)+d\left(y, v_{n+1}\right)}{2} \leq \psi^{n}\left(\frac{d\left(x, u_{1}\right)+d\left(y, v_{1}\right)}{2}\right)
$$

for each $n \geq 1$. Letting $n \rightarrow \infty$ in (3.14) and using Lemma 3.1, we get

$$
\lim _{n \rightarrow \infty}\left[d\left(x, u_{n+1}\right)+d\left(y, v_{n+1}\right)\right]=0 \text {. }
$$

This implies

$$
\lim _{n \rightarrow \infty} d\left(x, u_{n+1}\right)=\lim _{n \rightarrow \infty} d\left(y, v_{n+1}\right)=0 .
$$


Similarly, one can show that

$$
\lim _{n \rightarrow \infty} d\left(s, u_{n+1}\right)=\lim _{n \rightarrow \infty} d\left(t, v_{n+1}\right)=0 .
$$

From (3.15) and (3.16), we conclude that $x=s$ and $y=t$. Hence, $F$ has a unique coupled fixed point.

Example 3.7 (Linear case) Let $X=[0,1]$ and $d: X \times X \rightarrow \mathbb{R}$ be a standard metric. Define a mapping $F: X \times X \rightarrow X$ by $F(x, y)=\frac{1}{4} x y$ for all $x, y \in X$. Consider a mapping $\alpha: X^{2} \times X^{2} \rightarrow$ $[0,+\infty)$ be such that

$$
\alpha((x, y),(u, v))= \begin{cases}1 & \text { if } x \geq y, u \geq v \\ 0 & \text { otherwise }\end{cases}
$$

Since $|x y-u v| \leq|x-u|+|y-v|$ holds for all $x, y, u, v \in X$. Therefore, we have

$$
d(F(x, y), F(u, v))=\left|\frac{x y}{4}-\frac{u v}{4}\right| \leq \frac{1}{4}(|x-u|+|y-v|)=\frac{1}{4}(d(x, u)+d(y, v)) .
$$

It follows that

$$
\alpha((x, y),(u, v)) d(F(x, y), F(u, v)) \leq \frac{1}{4}(d(x, u)+d(y, v)) .
$$

Thus (3.1) holds for $\psi(t)=t / 2$ for all $t>0$, and we also see that all the hypotheses of Theorem 3.4 are fulfilled. Then there exists a coupled fixed point of $F$. In this case, $(0,0)$ is a coupled fixed point of $F$.

Example 3.8 (Nonlinear case) Let $X=\mathbb{R}$ and $d: X \times X \rightarrow \mathbb{R}$ be a standard metric. Define a mapping $F: X \times X \rightarrow X$ by $F(x, y)=\frac{1}{4} \ln (1+|x|)+\frac{1}{4} \ln (1+|y|)$ for all $x, y \in X$. Consider a mapping $\alpha: X^{2} \times X^{2} \rightarrow[0,+\infty)$ be such that

$$
\alpha((x, y),(u, v))= \begin{cases}1 & \text { if } x \geq y, u \geq v \\ 0 & \text { otherwise }\end{cases}
$$

Then we get

$$
\begin{aligned}
d(F(x, y), F(u, v)) & =\left|\frac{1}{4} \ln (1+|x|)+\frac{1}{4} \ln (1+|y|)-\frac{1}{4} \ln (1+|u|)-\frac{1}{4} \ln (1+|v|)\right| \\
& \leq \frac{1}{4}\left|\ln \frac{1+|x|}{1+|u|}\right|+\frac{1}{4}\left|\ln \frac{1+|y|}{1+|v|}\right| \\
& \leq \frac{1}{2}\left[\frac{1}{2} \ln (1+|x-u|)+\frac{1}{2} \ln (1+|y-v|)\right] \\
& \leq \frac{1}{2} \ln \left(\frac{2+|x-u|+|y-v|}{2}\right) \\
& \leq \frac{1}{2} \ln \left(1+\frac{|x-u|+|y-v|}{2}\right) \\
& =\frac{1}{2} \ln \left(1+\frac{d(x, u)+d(y, v)}{2}\right) .
\end{aligned}
$$


Thus,

$$
\alpha((x, y),(u, v)) d(F(x, y), F(u, v)) \leq \frac{1}{2} \ln \left(1+\frac{d(x, y)+d(y, v)}{2}\right) .
$$

Therefore (3.1) holds for $\psi(t)=\frac{1}{2} \ln (1+t)$ for all $t>0$, and also the hypothesis of Theorem 3.4 is fulfilled. Then there exists a coupled fixed point of $F$. In this case, $(0,0)$ is a coupled fixed point of $F$.

\section{Concluding remark}

The author of [33] recently established some coupled fixed point theorems in partially ordered metric spaces shortly by using some usual corresponding fixed point theorems on the metric space $M=X \times X$. Note that if the right-hand side of the $\alpha-\psi$-contractive type condition (3.1) is replaced by $\frac{1}{2}(d(x, u)+d(y, v))$, then a very short proof similar to what followed in [33] can be provided for a coupled fixed point theorem of Theorem 3.4 type by making just use of the results in [36]. However, since the right-hand side of (3.1) is not of the form $\frac{1}{2}(d(x, u)+d(y, v))$, specially for nonlinear functions $\psi$, then it is not possible to apply the method [33]. In this connection, notice that Example 3.7 works for both when the right-hand side is either $\frac{1}{2}(d(x, u)+d(y, v))$ or as in (3.1), but Example 3.8 works only for (3.1). Hence, our results are more interesting and different from the existing results of [33] and [36].

\section{Competing interests}

The authors declare that they have no competing interests.

\section{Authors' contributions}

The authors contributed equally and significantly in writing this paper. All authors read and approved the final manuscript.

\section{Author details}

'Department of Mathematics, Aligarh Muslim University, Aligarh, 202002, India. ${ }^{2}$ Department of Mathematics, Faculty of Science, King Abdulaziz University, P.O. Box 80203, Jeddah, 21589, Saudi Arabia. ${ }^{3}$ Department of Mathematics, Texas A\&M University-Kingsville, Kingsville, TX 78363, USA.

\section{Acknowledgements}

The work of the second author was funded by the Deanship of Scientific Research (DSR), King Abdulaziz University, Jeddah. He acknowledges with thanks DSR technical and financial support.

Received: 17 May 2012 Accepted: 29 November 2012 Published: 18 December 2012

\section{References}

1. Banach, S: Sur les opérations dans les ensembles abstraits et leur application aux équations intégrales. Fundam. Math. 3, 133-181 (1922)

2. Abbas, M, Nazir, T, Radenović, S: Fixed points of four maps in partially ordered metric spaces. Appl. Math. Lett. 24, 1520-1526 (2011)

3. Agarwal, RP, Meehan, M, O'Regan, D: Fixed Point Theory and Applications. Cambridge University Press, Cambridge (2001)

4. Agarwal, RP, El-Gebeily, MA, O'Regan, D: Generalized contractions in partially ordered metric spaces. Appl. Anal. 87, 109-116 (2008)

5. Bhaskar, TG, Lakshmikantham, V: Fixed point theorems in partially ordered metric spaces and applications. Nonlinear Anal. 65, 1379-1393 (2006)

6. Choudhury, BS, Kundu, A: A coupled coincidence point result in partially ordered metric spaces for compatible mappings. Nonlinear Anal. 73, 2524-2531 (2010)

7. Choudhury, BS, Maity, P: Coupled fixed point results in generalized metric spaces. Math. Comput. Model. 54, 73-79 (2011)

8. Ćirić, L, Cakić, N, Rajović, M, Ume, JS: Monotone generalized nonlinear contractions in partially ordered metric spaces. Fixed Point Theory Appl. 2008, Article ID 131294 (2008)

9. Luong, NV, Thuan, NX: Coupled fixed points in partially ordered metric spaces and application. Nonlinear Anal. 74 983-992 (2011) 
10. Nieto, JJ, Rodríguez-López, R: Contractive mapping theorems in partially ordered sets and applications to ordinary differential equations. Order 22, 223-239 (2005)

11. Nieto, JJ, Rodríguez-López, R: Existence and uniqueness of fixed point in partially ordered sets and applications to ordinary differential equations. Acta Math. Sin. Engl. Ser. 23(12), 2205-2212 (2007)

12. Ran, ACM, Reurings, MCB: A fixed point theorem in partially ordered sets and some applications to matrix equations. Proc. Am. Math. Soc. 132, 1435-1443 (2004)

13. Samet, $B$ : Coupled fixed point theorems for a generalized Meir-Keeler contraction in partially ordered metric spaces. Nonlinear Anal. 72, 4508-4517 (2010)

14. Ilić, D, Rakočević, V: Common fixed points for maps on cone metric space. J. Math. Anal. Appl. 341, 876-882 (2008)

15. Haghi, RH, Rezapour, S, Shahzad, N: Some fixed point generalizations are not real generalizations. Nonlinear Anal. 74, 1799-1803 (2011)

16. Haghi, RH, Rezapour, S: Fixed points of multi functions on regular cone metric spaces. Expo. Math. 28, 71-77 (2010)

17. Derafshpour, M, Rezapour, S, Shahzad, N: Best proximity points of cyclic $\varphi$-contractions on reflexive Banach space. Topol. Methods Nonlinear Anal. 37(1), 193-202 (2011)

18. Aleomraninejad, SMA, Rezapour, S, Shahzad, N: Some fixed point results on a metric space with a graph. Topol. Appl. $159,659-663(2012)$

19. Ghorbanian, V, Rezapour, S, Shahzad, N: Some ordered fixed point results and the property (P). Comput. Math. Appl. 63, 1361-1368 (2012)

20. Mohiuddine, SA, Alotaibi, A: On coupled fixed point theorems for nonlinear contractions in partially ordered G-metric spaces. Abstr. Appl. Anal. 2012, Article ID 897198 (2012)

21. Mohiuddine, SA, Alotaibi, A: Some results on tripled fixed point for nonlinear contractions in partially ordered G-metric spaces. Fixed Point Theory Appl. 2012, 179 (2012)

22. Nashine, HK, Kadelburg, Z, Radenović, S: Coupled common fixed point theorems for $w^{*}$-compatible mappings in ordered cone metric spaces. Appl. Math. Comput. 218, 5422-5432 (2012)

23. Sintunavarat, W, Cho, YJ, Kumam, P: Common fixed point theorems for $c$-distance in ordered cone metric spaces. Comput. Math. Appl. 62, 1969-1978 (2011)

24. Aydi, $\mathrm{H}$, Samet, B, Vetro, $\mathrm{C}$ : Coupled fixed point results in cone metric spaces for $\mathrm{W}$-compatible mappings. Fixed Point Theory Appl. 2011, 27 (2011)

25. Jeli, M, Cojbasic Rajic, V, Samet, B, Vetro, C: Fixed point theorems on ordered metric spaces and applications to nonlinear elastic beam equations. J. Fixed Point Theory Appl. (2012). doi:10.1007/s11784-012-0081-4

26. Nashine, HK, Samet, B, Vetro, C: Coupled coincidence points for compatible mappings satisfying mixed monotone property. J. Nonlinear Sci. Appl. 5(2), 104-114 (2012)

27. Samet, B, Vetro, C: Coupled fixed point, F-invariant set and fixed point of N-order. Ann. Funct. Anal. 1(2), $46-56$ (2010)

28. Samet, B, Vetro, C: Coupled fixed point theorems for multi-valued nonlinear contraction mappings in partially ordered metric spaces. Nonlinear Anal. 74, 4260-4268 (2011)

29. Sintunavarat, W, Kumam, P, Cho, YJ: Coupled fixed point theorems for nonlinear contractions without mixed monotone property. Fixed Point Theory Appl. 2012, 170 (2012)

30. Karapinar, E, Samet, B: Generalized $\alpha$ - $\psi$-contractive type mappings and related fixed point theorems with applications. Abstr. Appl. Anal. 2012, Article ID 793486 (2012)

31. Abdeljawad, T, Karapinar, E, Aydi, H: A new Meir-Keeler type coupled fixed point on ordered partial metric spaces. Math. Probl. Eng. 2012, Article ID 327273 (2012)

32. Abdeljawad, T: Coupled fixed point theorems for partially contractive type mappings. Fixed Point Theory Appl. 2012, 148 (2012)

33. Amini-Harandi, A: Coupled and tripled fixed point theory in partially ordered metric spaces with applications to initial value problem. Math. Comput. Model. doi:10.1016/j.mcm.2011.12.006 (in press)

34. Shatanawi, W, Samet, B, Abbas, M: Coupled fixed point theorems for mixed monotone mappings in ordered partial metric spaces. Math. Comput. Model. 55, 680-687 (2012)

35. Lakshmikantham, V, Ćirić, L: Coupled fixed point theorems for nonlinear contractions in partially ordered metric spaces. Nonlinear Anal. 70, 4341-4349 (2009)

36. Samet, B, Vetro, C, Vetro, P: Fixed point theorems for $\alpha$ - $\psi$-contractive type mappings. Nonlinear Anal. 75, 2154-2165 (2012)

doi:10.1186/1687-1812-2012-228

Cite this article as: Mursaleen et al.: Coupled fixed point theorems for $\alpha$ - $\psi$-contractive type mappings in partially

ordered metric spaces. Fixed Point Theory and Applications 2012 2012:228. 